\title{
A ORAÇÃO EM TEMPOS DE DISTANCIAMENTO SOCIAL
}

\author{
Ms. Pe. Rene Zanandréa* \\ DOI: https://doi.org/10.52451/teopraxis.v37i129.13 \\ Recebido: 03 de dezembro de 2018 | Aprovado: 11 de abril de 2019
}

Resumo: A oração dos cristãos se intensificou durante a experiência de distanciamento social provocada pela pandemia da Covid-19. Jesus rezava e ensinou a rezar desmistificando e libertando a própria oração. A Igreja precisa aprender de Jesus a rezar com o cotidiano e as Sagradas Escrituras; rezar mais pelos outros do que para si própria.

Palavras-chave: Oração. A oração de Jesus. Oração Cristã. A Oração do Papa Francisco. Distanciamento social.

\section{Introdução}

Jesus rezava e ensinou a rezar. Nos momentos cruciais de sua missão dialogou com o Pai. Em momentos limite, sua franqueza e, ao mesmo tempo, sua confiança no Pai revelam a firmeza e a determinação que sua oração proporcionava: "Agora estou muito perturbado. E o que vou dizer? Pai livra-me desta hora? Mas foi precisamente para esta hora que eu vim. Pai, manifesta a glória do teu nome!" (Jo 12,27-28).

Agora a humanidade se depara com uma experiência ímpar. A pandemia da Covid-19 tem forçado os povos do mundo inteiro ao isolamento. E, não raras vezes, têm feito a experiência de se reinventar, inclusive espiritualmente. Se o fiel crente reza no dia-a-dia é provável que nesses tempos a oração se fez mais intensa. Mas, a Palavra de Deus tem feito parte da oração cotidiana dos cristãos?

* Padre da Diocese de Vacaria. Mestre em Teologia pela Escola Superior de Teologia (EST) - São Leopoldo/RS. Professor da Itepa Faculdades. Áreas: Sacramentos, Liturgia, Comunicação, Organização Paroquial. Email: renezanandrea@yahoo.com.br 
No presente artigo recolhemos relatos de algumas experiências de oração vividas de modo distinto nesses tempos de distanciamento social. Essas experiências nós as encontramos em ações noticiadas nas mídias sociais, mas, também, através de entrevistas. Em Jesus, o Nazareno, buscamos inspirações: Ele se retirava para rezar e dá indicativos da oração autêntica. Por fim propomos as Sagradas Escrituras e o olhar para o cotidiano da vida como inspirações para a oração cristã.

\section{A oração no "deserto" do distanciamento social: relatos de experiências}

A pandemia do coronavírus impôs o isolamento social no Brasil a partir de março de 2020. Em outros continentes isso se deu bem antes. Surgiram alguns sentimentos que foram mutando com o passar dos dias. Pensava-se, por exemplo, que, com a cooperação de todos, tudo retomaria sua "normalidade" depois de algumas semanas. Foi necessário repensar essa intuição depois de se perceber o prolongamento desse estado de distanciamento.

Também o cultivo da fé sofreu seus impactos. A necessidade de fechar igrejas causou constrangimentos nos líderes religiosos, embora parecesse ser para um período breve. Mas foi necessário celebrar a Semana Santa, o Tríduo Pascal e a Ressurreição do Senhor ainda de portas fechadas... e os fiéis foram orientados a participar virtualmente e a ritualizar sua "presença" colocando na frente de sua casa os sinais que expressavam essa celebração da centralidade da fé cristã.

\subsection{A Missa transmitida nas redes sociais}

As atividades comunitárias foram quase todas suspensas ou adiadas. Com isso o cerne da vida comunitária, sua interatividade e proximidade física, ficaram bloqueados. Com a 
restrição das celebrações abertas ao público se iniciaram as transmissões on-line na maioria das comunidades paroquiais.

$\mathrm{O}$ alcance e a abrangência dessas transmissões ultrapassam as fronteiras da paróquia e acabam por alcançar outros lugares, mas, não necessariamente, chegam aos paroquianos locais. "Atingir" os paroquianos, permanece um desafio. Afinal, nem todos os que costumavam frequentar as igrejas usam as redes sociais; nem todos aprenderam a manusear os equipamentos de informática e têm acesso à internet. Basta ver que, mesmo atingindo outras realidades além das fronteiras geográficas da paróquia, o número de conexões durante a Missa é absolutamente inferior ao número de paroquianos.

Dentre os inúmeros desafios, nas Missas transmitidas pelas redes sociais aparecem a qualidade técnica (áudio, enquadramento de imagem, qualidade das conexões) e a interação com a comunidade. Houve certa estranheza porque não se tinha conhecimento de quem estava "assistindo" pela rede social e como reagia às celebrações. Isso tudo exigiu dos ministros uma maior responsabilidade e cuidado redobrado no preparo da liturgia.

Apareceram iniciativas como de pedir aos que acompanham as transmissões para que enviem suas intenções de oração, na rede social. $\mathrm{E}$ os internautas corresponderam e expressaram certa assiduidade, interagindo sistematicamente com as transmissões. Iniciativas como a leitura dessas intenções e o pedido de envio de fotos para compor um painel na Igreja, por exemplo, resultou em certa fidelização e interação mais palpável. Foram fixadas fotografias de fiéis nos bancos de algumas igrejas, sinalizando a memória dos ausentes. Tais métodos têm sido amplamente adotados e dado o efeito de as pessoas se sentirem mais envolvidas com as Missas. Há iniciativas de editoras distribuindo os subsídios litúrgicos que produzem e paróquias disponibilizando material digital para auxiliar os fiéis a rezarem em casa. 
As celebrações on-line dão visibilidade e, não raras vezes, isso acabou gerando dificuldades entre os membros das equipes, tornando evidente tensões que já existiam, embora veladas. Outro desafio constatado é a criatividade despudorada, criatividade "selvagem", atitudes que ferem o princípio cristão da centralidade no Mistério Pascal de Jesus Cristo.

Mas, embora tantos desafios e, em especial a realidade de uma Assembleia Litúrgica menos completa, precisamos reconhecer que, nesse tempo de exceção, as Missas transmitidas pelas redes sociais têm ajudado a alimentar a fé e a esperança de tantos que levam a sério o cuidado com a vida, ficando em casa.

E quando passar a pandemia, como nossas comunidades vão retornar? Os fiéis terão saudades da comunidade? Pode ser que alguns se percam e continuem isolados. Como re-encantar para a vida comunitária? E aquelas pessoas que perderam seus familiares, seus empregos, empobreceram?

\subsection{Experiências de oração pessoal e familiar}

O distanciamento social forçou a ficar em casa. Para além de ter onde morar, ter o que comer e vestir, a espiritualidade, a esperança constituem o rol das necessidades básicas de toda pessoa. A Igreja das casas está se reinventando pois todos precisam continuar tendo razões para viver. E "essas verdadeiras 'Igrejas domésticas' se conectaram entre si, unindo pessoas, famílias, grupos e comunidades em encontros de oração e formação", afirma Moisés Sbardelotto.

Para elaborar as linhas a seguir, realizamos uma pesquisa através de uma rede social obtendo respostas de doze pessoas. A contribuição vem de religiosas, de fiéis leigos e de presbíteros ${ }^{1}$. Num primeiro contato pedimos que, de forma bem aberta, partilhassem o modo como estão rezando nesses tempos de

1 Os depoimentos incorporados ao texto serão identificados, porém mantendo o anonimato dos entrevistados. 
distanciamento social. O segundo contato foi para saber da participação ou não das Sagradas Escrituras na oração pessoal e familiar.

Quase por unanimidade as pessoas afirmaram que a oração se tornou mais intensa: "percebi que passei a dedicar mais tempo para conversar com Deus, falar dos meus medos, preocupações, pedir proteção e a superação dessa crise" relatou uma entrevistada. Outra disse que, em família, não tinham o hábito de fazer a oração juntos, diariamente, [exceto] nos finais de semana, antes de dormir. Mas, "nesse período [de pandemia], todos os dias, às 10 horas [da noite], eu coloco o relógio despertar e a gente reza juntos. Esse foi um ponto positivo nesse período".

"A oração é um espaço onde nos encontramos conosco mesmos e com o Senhor. É o que nos fortalece. Se a gente não tem uma vida de oração, nessas tribulações da vida a gente desiste e perde a razão de viver", relatou uma pessoa entrevistada. E outra prossegue relatando que "já rezava o meu Rosário, fazia visita quase diariamente ao Sacrário e participava de boa parte das Celebrações Eucarísticas [mas] foi muito difícil... Parecia que tinham me tirado a Igreja. Tive que começar a me reinventar na oração. E foi muito bom".

Vários entrevistados revelaram elementos que compõem sua oração, seu conteúdo. Eis algumas respostas: "agradecer por tudo que Ele tem me proporcionado"; "como núcleo [de religiosas] nos comprometemos a estar em unidade umas com as outras e em sintonia com o povo que, nesta situação, tem muita incerteza, desânimos, dúvidas e choque por tantas vidas ceifadas por um vírus invisível e fatal".

Sobre os métodos de oração, trazemos algumas manifestações: "costumo rezar o Terço, ouvir reflexões sobre a vida e a necessidade de alimentar a fé e a esperança"; "em minha família a reza do Terço tornou-se mais regular e os momentos juntos ganharam mais prioridade"; "consegui rezar os vinte Mistérios meditados e [com mais tempo] consegui rezá-lo 
melhor"; "o silêncio favorece muito minha conexão com Deus, bem como um espaço orante, com Bíblia, imagem de Cristo e de Nossa Senhora”. Outras citaram a Missa na casa religiosa e a Celebração da Palavra na comunidade aos domingos. Um padre testemunhou ter descoberto "uma força ainda maior [...] vinda da Eucaristia. [...] Nunca tinha celebrado a Eucaristia sozinho. Foi desafiador no início, mas muito gratificante, agora. [...] Celebrei várias vezes com minha família (nunca havia feito só com meus pais)". Também a oração antes do almoço foi citada com o testemunho de que "já sentimos o efeito [e] a nossa casa começou a ser mais Igreja”. Várias respostas indicaram a relevância da oração no contato com a obra do Criador: é muito bom "se dar conta que Deus está presente ali... tinha dias que parecia que tudo rezava comigo, sabe?”. A oração permite perceber "um Deus que corrige e salva”. Quase que a totalidade das falas citaram as celebrações via redes sociais como forma de rezar. Foram citadas as transmissões via Facebook e TVs de inspiração católica, a produção de lives formativas e os materiais enviados eletronicamente que ajudam a rezar. "Há situações em que parece que Deus transpassa da tela para o coração da gente. São experiências que agora a gente começou a valorizar e Deus [...] derramou muito mais amor do que já tinha para que todos experimentássemos [como que] dizendo pra gente: "você não está sozinho"”.

Os entrevistados apontaram, também, desdobramentos da oração na convivência e no serviço. Uma religiosa testemunhou que percebe Deus agindo em resposta ao serviço que presta a uma comunidade terapêutica: "independentemente do que 'aprontaram' [...] o fato de eles se manterem em pé é um jeito de sentir que Deus está conosco”. Um sentimento comum é a "falta do convívio em comunidade, das celebrações dominicais, da partilha da vida"; "estamos distanciados, impossibilitados de nos encontrarmos para rezarmos juntos”. Outras experiências ressaltam a mesma importância da coletividade: "minha fé não 
se abalou porque no [movimento juvenil tal] tenho cada vez mais forças para não me deixar abalar [...] e sair para o mundo com aquele intuito de mudá-lo, acredito que isso seja possível sim"; "a convivência com o outro padre é muito bacana onde um ajuda o outro". Aparece a preocupação com os problemas do isolamento: "as pessoas estão muito doentes e têm vindo procurar orientação psicológica [espiritual]. [Temos] que estar bem preparados. As pessoas, as famílias estão se fechando muito e, se não trabalhar, vai estourar em doenças. [...] Irmãos no sacerdócio não ligam pra saber como está o outro, não visitam. [Eu] tenho procurado ligar". Um outro padre disse sentir "falta das reuniões e formações comunitárias, das celebrações onde se pode abraçar e querer bem, se acolher na porta com abraços... agora a gente se acolhe só com o cotovelo". Mas, testemunhou alguém, tudo isso "nos levou a despertar e valorizar mais a solidariedade, a empatia e fazer do distanciamento um ato de amor para com os demais".

A oração alimenta a esperança, mantém em pé, testemunham os entrevistados: fiéis leigos afirmam ter "a certeza de que Deus continua caminhando conosco e a cada dia nos dispõe e nos dá coragem de recomeçar na esperança"; vamos "tentando passar isso também para as outras pessoas" na "fé e esperança por dias melhores". Um jovem presbítero relatou que o isolamento forçado o "fez chorar e sentir desânimo na missão". Então rezou como ainda não tinha rezado: "tempo em silêncio para falar com Deus e ouvi-Lo... [...] nunca tinha passado tempo significativo em frente ao sacrário [e da] imagem de Nossa Senhora". Mas "foi o tempo da graça, me encontrei [...], como um retiro" podendo revisitar momentos da infância, família, comunidade, escola, seminário... "Revisitei meus erros e pensei sobre os obstáculos". Também o Papa Francisco foi lembrado quando uma fiel leiga disse que suas mensagens despertaram para a necessidade da oração. A família ganhou novas percepções: "tem seus erros e defeitos, 
mas aqui tem Deus, aqui é que Deus mora e quer a gente mais perto. E pudemos experimentar essa presença de Deus em nossa vida". Uma entrevistada intui que "nunca mais vai ser igual, depois dessa pandemia. O participar das celebrações, o fazer uma oração não vai ser igual a antes. O valor é muito maior, hoje, da família, do ser das pessoas, da natureza”.

Nosso segundo contato com os entrevistados buscou saber como contemplam (ou não) a Palavra de Deus, já que apenas duas entrevistadas a citaram na primeira resposta. Disseram: "com mais tempo em casa pude fazer com mais calma a oração da Palavra de Deus”; “em meus momentos de orações, não todos, gosto de ler um trecho da Bíblia; geralmente acompanho a liturgia diária e, a partir da leitura, faço um momento de reflexão”. Alguns disseram que seguem os passos do Método de Leitura Orante: "gosto muito"; "às vezes utilizando o MLO e às vezes simplesmente partilhando em comunidade [religiosa]"; "sempre que possível, faço a leitura orante". Os padres entrevistados são unânimes em afirmar que o contato diário serve para consumo próprio mas, também, para partilhar em comunidade através das homilias: "faço a opção de todas as manhãs, rezar com a liturgia diária ao invés da liturgia das horas"; "a liturgia diária me prepara também para as celebrações e me motivam a buscar sempre reflexões e estudos exegéticos/hermenêuticos para compreender o sentido mais profundo do texto". Inúmeras outras falas testemunham a importância dos textos sagrados para a oração: "o contato com a Palavra me traz esperança e acalento neste momento difícil; e me faz ver o quanto Deus é amoroso e misericordioso"; "a Palavra de Deus vem como luz, abre horizonte, mostra caminhos"; "acompanho a liturgia diária, principalmente com o Evangelho e o Salmo"; "geralmente a Palavra de Deus, mesmo sendo da liturgia do dia, parece que se encaixa naquilo que estou vivendo, a situação daquele dia”; "a Sua Palavra me traz paz, segurança, me faz tomar posição tentando viver lá em meio 
aos desafios do dia-a-dia, me dá forças, faz com que nunca me sinta só"; "muitas vezes eu disse, após rezar com a Palavra: "ainda bem que eu tenho Deus que me ajuda, que me entende, que me levanta, me faz recomeçar"'; "acompanho a transmissão da missa diariamente, ouço com atenção a proclamação dos textos Bíblicos e reflexões... procuro colocar em prática o que a Palavra de Deus me transmite".

O isolamento social está forçando a espiritualidade e a oração cristã a se reavivarem. É notório que a oração pessoal e familiar tem tomado elementos mais palpáveis da vida. Mais adiante veremos que Jesus ensina assim. Portanto temos um longo e belo caminho pela frente.

\subsection{0 "mundo inteiro" está rezando diferente}

Neste terceiro (e breve) item queremos mencionar as incontáveis iniciativas de oração pelo mundo afora e que têm feito uso de uma gama sem fim de recursos eletrônicos e com sintonia global.

É impossível não mencionar aqui a oração que o Papa Francisco fez pelo mundo inteiro na praça da Basílica São Pedro na tarde cinzenta de 27 de março. Essa iniciativa do Sumo Pontífice e o jeito como rezou, impactou o mundo. A cena televisiva mostrava um "senhorzinho" que caminhava sozinho. Mas ele não estava só porque o mundo inteiro estava presente naquela "subida", naquela oração.

Vimos um Papa diferente, que reza diferente, mas tendo presente as preocupações evangélicas de sempre. Francisco disse, na homilia: "Na nossa avidez de lucro, deixamo-nos absorver pelas coisas e transtornar pela pressa. Não nos detivemos perante os teus apelos, não despertamos face a guerras e injustiças planetárias, não ouvimos o grito dos pobres e do nosso planeta gravemente enfermo. Avançamos, destemidos, pensando que continuaríamos sempre saudáveis 
num mundo doente. Agora nós, sentindo-nos em mar agitado, imploramos-Te: 'Acorda, Senhor!'. [...] Com a tempestade, caiu a maquilhagem dos estereótipos com que mascaramos o nosso 'eu' sempre preocupado com a própria imagem; e ficou a descoberto, uma vez mais, aquela (abençoada) pertença comum a que não nos podemos subtrair: a pertença como irmãos. [...] Não somos autossuficientes, sozinhos afundamos: precisamos do Senhor como os antigos navegadores, das estrelas. Convidemos Jesus a subir para o barco da nossa vida. [...] Ele serena as nossas tempestades, porque, com Deus, a vida não morre jamais".

Muitas outras iniciativas de oração unindo os cinco continentes se fizeram saber. Mencionamos aqui - como ilustração - o evento de oração on-line intitulado "eu não consigo respirar". Aconteceu no dia 23 de julho por iniciativa da vida religiosa consagrada. Teve o objetivo de "fortalecer a fé e testemunhar a presença de Deus unindo o mundo que enfrenta a pandemia do Covid-19 [e esteve] direcionada especialmente às pessoas dos países que estão sofrendo drasticamente com as consequências do coronavírus”.

Para participar as pessoas precisaram se inscrever, pois o encontro mundial aconteceu em modalidade de videoconferência pela plataforma Zoom. A presidente da União Internacional das Superioras Gerais (UISG), Ir. Jolanta Kafka, descreveu o momento vivido como de "santa inquietação" pela privação de projetos e de poder administrar a própria vida. "Um tipo de 'pobreza' e de 'incerteza' que levam a confiar em Deus mais sinceramente, a aceitar que a insegurança eduque a uma busca intensa de Deus, a ancorar o coração n'Ele”. Ela lembrou que o confinamento ajudou a "redescobrir o próximo, com gestos concretos de ajuda mútua, em nível local ou através da 'solidariedade global'. Por isso, a oração on-line se manifesta como mais uma iniciativa para oferecer o acompanhamento 
recíproco, mesmo que de forma virtual, mas que vai muito além da comunidade congregacional".

A experiência da pandemia tem possibilitado perceber a caducidade de vários valores que considerávamos primários e que os percebemos secundários e vice-versa. O Papa Francisco, lembrou disso na oração de 27 de março: "a tempestade desmascara a nossa vulnerabilidade e deixa a descoberto as falsas e supérfluas seguranças com que construímos os nossos programas, os nossos projetos, os nossos hábitos e prioridades. Mostra-nos como deixamos adormecido e abandonado aquilo que nutre, sustenta e dá força à nossa vida e à nossa comunidade". Oxalá essa experiência de distanciamento social também nos ajude a rezar diferente. Se faz necessário aprender com Jesus. É o que buscamos a seguir, revisitando trechos evangélicos que mostram esse Caminho.

\section{A oração de Jesus: inspiração para a oração da Igreja}

Por ser uma das formas de contato com a divindade, a oração se relaciona com a experiência de sentido e de totalidade. Não se trata apenas de um movimento vertical, mas também horizontal. E isso se faz exigência no que diz respeito à coerência da oração cristã para que seja, de fato, cristã.

A experiência de sentido e de transcendência acontece na práxis (ação-reflexão), segundo Jon Sobrino. Mas o "mais" que nasce dessa práxis deve ser considerado para que se manifeste a experiência de gratuidade e, assim, o cristão se encontre consigo mesmo ${ }^{2}$.

A oração é uma experiência de gratuidade. Esse ato "ocioso" nos lembra que o Senhor está além das categorias do útil e do inútil. A gratuidade de Deus nos provoca para uma experiência que liberta da alienação. O cristão comprometido com o Reino

2 Jon SOBRINO, A oração de Jesus e do cristão, p.9. 
precisa encontrar os caminhos de uma oração autêntica, que vai além do discursivo. $\mathrm{O}$ encontro com esse Deus gratuito nos despoja, despe.

A oração comunitária se dirige a Deus e se faz dentro de um contexto bem determinado. Os conceitos cristãos de Deus, Reino, seguimento, gratuidade, etc também estão sob determinada condição histórica. Portanto não podem ser considerados como abstratos e intemporais, mas situados historicamente já que se deduzem da história concreta de Jesus, afirma Sobrino.

\subsection{A oração de Jesus}

A oração dos cristãos se inspira na oração de Jesus. Ora, "se Jesus é o Filho, o Primogênito, o primeiro dentre os crentes, é também o primeiro dos orantes" ${ }^{3}$. E, uma vez que Jesus rezou desde o seu contexto histórico, se deduz que a oração é uma faceta da vida e que a oração responde às tramas e aos dramas humanos.

Um dado fundamental é que Jesus rezava. E o conteúdo e o contexto de sua oração estão bem situados e assim deve ser a oração cristã. Jesus não foi ingênuo em relação à oração; não a exercitou por mera rotina ou tradição. E, além disso, Ele desmistificou a oração.

Continuando a reflexão com Jon Sobrino vemos que Jesus, em sua oração, observa e denuncia os perigos inerentes à oração ${ }^{4}$. Vamos a algumas situações que dão exemplo disso. Em Lc 18,11, um fariseu agradece por não ser como os outros. Jesus condena essa oração por ser autoafirmação egoísta. Falta a necessária "alteridade" com o polo referencial que precisa ser Deus. Desse modo a oração é um mero mecanismo narcisista e gratificante; é autoengano. Atualmente o Papa Francisco também tem chamado a atenção da Igreja para que supere a

3 Jon SOBRINO, A oração de Jesus e do cristão, p.11.

4 Jon SOBRINO, A oração de Jesus e do cristão, p.13. 
tentação da auto referencialidade.

Outro texto mostra a hipocrisia da visibilidade das manifestações religiosas: supõe que se consegue a fama de ser homem bom, justo. Em Mt 6,5a: "para serem vistos pelos homens”. A oração supõe a atitude de pobreza diante de Deus, mas a oração do fariseu pretende uma expressão de grandeza. Jesus mostra que a autêntica e boa fama é conferida por uma oração que é expressão das obras de justiça e caridade.

"Quando vocês rezarem, não usem muitas palavras [...]. Eles pensam que serão ouvidos por causa do seu palavreado" (Mt 6,7s). Jesus critica a oração mecânica e mágica dos palavreados que veem na repetição de fórmulas uma correta relação com Deus. Ele rejeita a oração que não é expressão do mais profundo do ser que ora e a autonomia absoluta que se dá à oração (sacralizando-a em fórmulas).

Jesus também critica a oração alienante. A oração sem ação é vã. Meramente clamar "Senhor, Senhor" não é expressão de uma práxis. É no fazer o que seja a vontade de Deus, que se manifesta a "ultimidade" de sentido". É o que vemos em Mt 7,21: não basta chamar ao Senhor. "Só entrará [no Reino] aquele que põe em prática a vontade do meu Pai, que está no céu."

E em Lc 12,38-40: "Tenham cuidado [...]. Eles [...] exploram as viúvas e roubam suas casas e, para disfarçar, fazem longas orações”. O que se condena aqui é a oração que se converteu em mercadoria. Faz lembrar Oséias (4,6ss) que diz que os sacerdotes "se alimentam das vítimas oferecidas pelo pecado e por isso lhes convém que o meu povo continue pecando”. O mau uso do templo, sua perversão é o alvo da crítica de Jesus.

Por fim a citação de Lc 3,21 em que Jesus, depois de batizado, estava rezando. "E do céu veio uma voz: 'Tu és o meu

5 Jon SOBRINO, A oração de Jesus e do cristão, p.15. 
Filho amado! Em ti encontro o meu agrado". E mais adiante (Lc 9,29), "enquanto rezava, seu rosto mudou de aparência e sua roupa ficou muito branca e brilhante". Mais que palavras de Jesus temos aqui uma reflexão de Lucas. Nas narrações do batismo e da transfiguração aparecem fenômenos maravilhosos que enfeitam o essencial: a unção com o Espírito, a consciência de Jesus sobre a sua própria missão, a filiação única de Jesus.

Todas essas passagens mostram Jesus consciente e conhecedor das falsificações típicas da oração. Doutro lado os Evangelhos mostram Jesus em atitude de oração. Vemos Jesus que abençoa a mesa, observa o culto sabático e reza junto com a comunidade. Vemos Jesus rezando quando precisa tomar decisões sintonizado com acontecimentos históricos e em conexão explícita com o Pai. O vemos rezando em momentos de decisões importantes como eleger os doze, ensinar o Pai Nosso, etc. Vai ao monte, a um horto, ao deserto. Distancia-se de sua atividade pública, embora isso não signifique separação da práxis da vida. A oração lhe era habitual, reza em situações históricas concretas.

Há, ainda ocasiões em que Jesus condensa o mais profundo de sua vida e missão numa oração: "Eu te louvo, ó Pai, Senhor do céu e da terra, porque ocultaste essas coisas aos sábios e doutores e as revelastes aos pequeninos" (Mt 11,25; Lc 10,21). Jesus dá graças porque fez-se o que parecia impossível: quem parecia poder compreender não compreende, mas compreenderam os que pareciam não consegui-lo. Jesus reza ao Pai dizendo "muito obrigado" porque aconteceu algo inesperado e maravilhoso, uma atividade histórica com profunda experiência de sentido.

Outra oração referencial de Jesus é a do Horto: "Pai [...], afasta de mim este cálice; porém, não o que eu quero, mas o que tu queres" (Mc 14,35; Mt 26,39; Lc 22,41)\}. Quando a crise questiona o sentido de sua vida, Jesus vai para a oração, coloca- 
se diante do Pai. A oração do Horto condensa a crise de Jesus durante toda a sua vida. É uma oração que desemboca numa ação histórica: a decisão de ser fiel até o fim.

Enfim, a oração de Jesus vai se manifestando na busca da vontade do Pai, na alegria da chegada do Seu Reino, na aceitação fiel da Sua vontade até o fim e na confiança incondicional a Ele. Orar, para Jesus, é expressar-se em totalidade. A oração de Jesus é como é, porque nasce de uma determinada compreensão de alguém que lhe é referência: um Deus bem determinado.

\subsection{A oração da Igreja}

Sem esquecer que antes de ser templo, a Igreja foi casa e aí começou a experiência cristã, também é verdadeiro o pensamento de S. João Crisóstomo: "Se é verdade que tu podes rezar em casa, não te será, todavia, possível rezar do mesmo modo como se reza na assembleia”. Para Goffredo Boselli, a Liturgia é escola de oração: "O verdadeiro culto cristão empenha o homem em sua inteireza. E a manifestação ritual do culto existencial acontece através de um 'culto de palavra', ou seja, a oração". Significa que, quanto mais o homem é plenamente palavra, ou relação, tanto mais ele é plenamente ele mesmo. E a liturgia é um importante lugar onde o cristão é educado à oração. E é Deus quem educa seu povo para a oração através da Liturgia. É Deus, antes de tudo, que ensina seus filhos a rezarem.

A oração litúrgica segue um movimento, uma dinâmica. Três elementos que se sucedem: escuta, interiorização, interpretação. A liturgia educa para a oração indicando "a primazia da escuta da Palavra de Deus contida nas Escrituras". Significa que a palavra humana é segundo ato, como resposta. É

6 Goffredo BOSELLI, O sentido espiritual da Liturgia, p.142.

7 Goffredo BOSELLI, O sentido espiritual da Liturgia, p.148. 
importante a consciência de que é Deus a origem da oração; Ele é a sua causa e razão. Assim, toda a oração litúrgica deve ser fortemente marcada pela primazia da Palavra de Deus. Se a liturgia fala a língua das Escrituras, com o tempo o fiel poderá se alimentar da Palavra, memorizá-la, criar dentro de si um coração bíblico, afirma Boselli.

Depois, a oração nascida da escuta da Palavra deve ser interiorizada por cada orante. Se a liturgia não educa para a interiorização, ela não atinge seu fim educativo. Ela deve predispor tempo de escuta e tempo de silêncio.

Mas a oração é também ato de interpretação, tentativa de decodificar e tomar consciência de algo obscuro. Ao rezar preciso saber colocar em relação o sentido objetivo do texto e o sentido subjetivo que o texto indica. Assim, a liturgia, como sábia pedagoga, educa o cristão a ir além da própria liturgia, a fim de alcançar, na oração, a comunhão com Deus.

A oração cristã, é ato gratuito. Assim como Deus "desce" ao nosso encontro, nós, deixando-nos tomar pela mão e abandonando o nosso "eu" encontramos no absolutamente Outro a referência para nossa ação e reflexão. Desse modo a vontade de Deus faz um caminho em nós, como ensina o Papa Francisco: da cabeça (entendimento) ao coração (sentimento) e do coração às mãos (ação).

\section{Rezar... e de preferência com a Palavra inspirada}

Recentemente escutei um professor dando alguns conselhos a respeito da oração, numa palestra on-line. Foi importante constatar com ele que a pior forma de oração é não rezar. Disse ainda que existe uma coisa fundamental na oração que é o silêncio; que rezar requer humildade, entrega, confiança em Deus; sugeriu rezar com mantras: “cante várias vezes e depois deixe que Deus te fale ao coração; recomendou a oração em família: "como é importante... seja no almoço, ou na janta... 
quando se reza em família, Deus desce pra fazer morada naquela casa; e, muito importante, recomendou a Leitura Orante da Palavra de Deus: "comece lendo, simplesmente".

Um retrato das comunidades, no livro dos Atos dos Apóstolos, testemunha a perseverança dos primeiros cristãos "em ouvir o ensinamento dos apóstolos, na comunhão fraterna, no partir o pão e nas orações" (At 2,42). Isso que costumamos chamar de "pilares", se constitui em ideal de Igreja e projeto para um mundo possível.

Uma significativa parcela da população reza. Porém, o fato de poucos terem citado a oração com as Sagradas Escrituras na primeira rodada de entrevistas, deve preocupar. Reafirma uma intuição de que os cristãos católicos ainda não valorizamos o bastante a primazia da Palavra de Deus na oração que necessita ser diálogo. Doutro lado uma parcela significativa de entrevistados informou que reza com o calendário bíblico da Igreja. E é louvável quando, também nas celebrações da Igreja seja nos Sacramentos ou sacramentais ou nas demais celebrações da vida - os textos escolhidos sejam precisamente os indicados pelo calendário litúrgico. O "Ano Litúrgico", grosso modo, já estava constituído desde o século IV e vai sendo aperfeiçoado ao longo dos tempos.

Será importante reaprendermos com Jesus. Ele reza especialmente na observação do cotidiano, com "a Lei e os Profetas" e na escuta à vontade do Pai.

Isso se constitui desafio para as nossas liturgias que precisam ser menos aéreas, das nuvens, teóricas (palavrório). Urge trabalhar, orientar e formar para que os agentes da liturgia possibilitem a oração encarnada, que contemple e valorize o veio da Palavra e o veio da encarnação, a sensibilidade do cotidiano com suas vitórias e desafios. Também as reflexões (homilias) precisam ser bíblicas, que busquem entender o texto no seu contexto originário e que provoquem conversão no tempo presente. 
Há que se promover oração e uma liturgia que possibilite ao humano perceber-se pobre, que encontra suas seguranças não nas coisas, mas na busca intensa e sincera de Deus; uma oração e uma liturgia que eduque a ancorar o coração n'Ele e a redescobrir o próximo, com gestos concretos de ajuda mútua; oferecer o acompanhamento recíproco, mesmo que de forma virtual, mas que vai muito além do nosso pequeno círculo existencial.

Há uma gama enorme de pessoas que estão em busca. Citando um teólogo ortodoxo, Tomás Halik afirma que "sabemos onde a Igreja está, mas não sabemos onde não está"8. E sugere que nos desafiemos a procurar novamente Cristo. Aproveitar a pandemia como Kairós: um "momento oportuno para nos 'fazermos ao largo' e procurar uma nova identidade para o Cristianismo, num mundo que muda radicalmente sob os nossos olhos.

$\mathrm{Na}$ gratuidade de Deus, buscar inspiração para ações gratuitas também. Na música "ComunicArt", o Pe. Zezinho (CD “Alpendres, Varandas e Lareiras" de 1999) canta: "Todos os dias faço uma oração [...] por mim, pelo mundo, por algum irmão [...] com um Salmo ou [...] me renovo pela oração. Rezo pra que as coisas mudem, mas, sem ódio, sangue ou opressão [...]. Quero que a revolução da paz seja feita no meu coração”.

E o mesmo padre, durante uma homenagem que recebeu em Aparecida/SP em julho/2014 disse que precisamos "rezar olhando as situações presentes (notícias mundiais e locais; acontecimentos cotidianos); é preciso saber para quem e porque ora; rezar não pode ser algo que eu tiro da minha devoção; não pode ser só algo que eu estou com vontade de falar; precisa partir da necessidade do povo, do mundo; precisamos orar mais

8 Tomás HALIK, O Sinal das Igrejas Vazias: para um cristianismo que volta a partir, p.16. 
pelos outros do que por nós mesmos; é um serviço que a Igreja presta; se somos chamados a anunciar Jesus, temos a grave obrigação de saber porque oramos; e mais: saber orar do jeito da Igreja (com seu ensino); um cristão não pode ser favorável ao aborto, ao divórcio; um cristão não pode determinar o que Deus deve fazer ou não; o Reino de Deus cresce, não porque se tem dinheiro mas cresce porque você serve/ajuda o outro". E encerra: "nosso canto não é nosso, nosso talento não é nosso, nossa palavra não é nossa. Se não for dado à Igreja não é bom, é desperdício. Que Deus nos encontre sempre fiéis; que nos faça gente que mais ouve do que fala; e, se falar, falemos coisas que valham à pena".

Nosso tempo pede por uma Igreja que reza e ensina a rezar a partir da Revelação, com o olhar para a Utopia do Reino e com os pés firmados no tempo presente onde Deus nos plantou. "Da mesma forma como a chuva e a neve [...], a minha palavra que sai de minha boca não volta para mim sem efeito [...], a missão para a qual eu a mandei” (Is 55,10 ).

Atendamos ao apelo da Igreja que há tempos insiste na Lectio Divina como método bastante apropriado para acolher em nós a Palavra de Deus. É tão relevante essa indicação que está proposta nas Diretrizes Gerais da Ação Evangelizadora 2019-2022 e em alguns outros documentos da Igreja no Brasil. Oxalá o "deserto" dessa pandemia faça germinar em nós um jeito novo de rezar, parecido com o de Jesus; e comprometa a liturgia da Igreja na tarefa que é sua: ensinar a rezar pelo jeito como reza (mistagogia).

\section{Concluindo}

O Papa Francisco, na audiência geral do dia 19 de agosto de 2020, disse: "A resposta à pandemia é dupla: por um lado, é essencial encontrar uma cura para um vírus pequeno, mas terrível que põe de joelhos o mundo inteiro; por outro temos de 
curar um grande vírus, o da injustiça social, da desigualdade de oportunidade, da marginalização e da falta de proteção para os mais débeis. Nesta dupla resposta de cura há uma escolha que, segundo o Evangelho, não pode faltar: é a opção preferencial pelos pobres. E esta não é uma opção política; nem mesmo uma opção ideológica, uma opção de partidos... Não. A opção preferencial pelos pobres está no centro do Evangelho. E o primeiro a fazê-lo foi Jesus, como vemos na Carta aos Coríntios: Ele sendo rico se fez pobre para nos enriquecer. Fezse um de nós e, por isso, no centro do Evangelho existe esta opção, no centro do anúncio de Jesus" .

As convicções desse Papa só podem ser inspirações alcançadas na oração fundamentada na Palavra de Deus. Francisco reza pelo mundo e com o mundo, sua história. A oração cristã fundamentada nos textos sagrados consegue libertar e encorajar. Liberdade e encorajamento que foram experimentadas por incontáveis testemunhas da Ressurreição como, por exemplo, Dom Pedro Casaldáliga que viveu sem luxo e quis ser sepultado no chão, à beira do rio em São Félix do Araguaia, na "mais bonita de todas as catedrais do mundo: a criação" (a citação é a legenda de uma foto do local onde foi sepultado, postada numa rede social no dia 12/8/2020).

\section{Referências bibliográficas}

BOSELLI, Goffredo. O sentido espiritual da Liturgia. Trad.: Monjas Carmelitas Descaças do Mosteiro Santa Tereza de São Paulo. Brasília: Ed. CNBB, 2014.

FRANCISCO, Papa. O itinerário da Palavra de Deus: ouvido, coração e mãos (Homilia, 31/1/2018).

FRANCISCO, Papa. Texto integral da homilia do Papa Francisco neste 27 de março. Acesso em: https://www.vaticannews.va/pt/papa/news/2020-

9 Vídeo: Festa da Comunicação na Igreja, em 2h03min28seg. 
03/papa-francisco-homilia-oracao-bencao-urbe-et-orbi-27-marco.html HALIK, Tomás. O Sinal das Igrejas Vazias: para um cristianismo que volta a partir. São Paulo: Paulinas, 2020. (Texto original em checo).

SBARDELOTTO, Moisés. Virtualização da fé? Reflexões sobre a experiência religiosa em tempos de pandemia. In: Revista IHU on-line. Publicação do dia 20/7/2020. Acesso em:

http://www.ihu.unisinos.br/601104-virtualizacao-da-fe-reflexoes-sobre-aexperiencia-religiosa-em-tempos-de-pandemia.

SOBRINO, Jon. A oração de Jesus e do cristão. Trad.: Maria Joana de Brito. São Paulo: Loyola, 1981. (original: México, 1977).

Vídeo: Festa da Comunicação na Igreja - 25/07/2014. Link: https://www.youtube.com/watch?v=Nppf3bT6wxo. 